\title{
Opportunities of Multifunctional Centers for Formation and Development of Digital Society
}

\author{
Irina Andreeva ${ }^{1 *}$, Yurii Ciuvashin ${ }^{2}$, and Alexander Khoperskov ${ }^{1}$ \\ ${ }^{1}$ Volgograd State University \\ ${ }^{2}$ Multifunctional centre of Volgograd
}

\begin{abstract}
This article discusses the possibilities of using blockchain technology to modernize and improve the operation of work, which provides federal and regional services to citizens. The work of multifunctional centers of the Volgograd region and modernization of services are considered. In the article, the authors paid special attention to the analysis of the principles of developing the information infrastructure of the regional administration. In particular, the experience of building the information infrastructure in the regions of the Russian Federation was examined, the main components of the information infrastructure were identified, the structure of its main elements was examined. The work analyzed the existing problems faced by regions in the construction and implementation of the information infrastructure of the regional government.
\end{abstract}

\section{Introduction}

The world is moving towards direct interaction between people on the principles of peer-to-peer - equal to equal. There was a revolution! This is clearly seen in the coup in the mass media: newspapers, magazines and TV were the main information providers until the 1990s. Today, opinion leaders are bloggers, Youtube channels and social networks; money is invested in crowdfunding and $\mathrm{ICO}$, and information is stored in decentralized cloud systems [1, 2].

New technologies can be built on the developing technology of blockchain; how to do it, we will consider further.

\section{New potential opportunities for creating distributed databases using the blockchain}

The system of decentralized products and services, which is based on distributed registries and needed as a suitable technological environment, can be created [3]:

1. High speed of execution (in seconds) together with the ability to handle simultaneously a huge number of transactions (hundreds of thousands per second) with a low cost of each transaction.

2. A system, where all parts and elements, which necessarily are needed for good qualified decentralized services, can exist.

These are two big and basic tasks that currently hamper the development of peer-to-peer products.

It is possible to realize such interaction using emerging blockchain technology [4, 5]. Blockchain is essentially a distributed database. The technology of blockchain is different from the traditional database architecture and from the principle of the organization. The databases used on the Internet, as a rule, are based on the client-server architecture. In contrast, the introduction of blockchain provides the principle of the absence of a single server and the equal participation of all users.

When you use a standard database, a user who has an account and a password to it can modify the records stored on the centralized server. Whenever the accesses the server through a computer, the computer sends an updated version of the information. The control of the system is in the hands of the administrators who check its work.

In the blockchain everything is arranged differently. After one of the participants update the data on the network, all nodes need to confirm these changes. All information is stored on the computers of all users, and not on a single server, which ensures the protection of the system from threats of hacking and cyber-attacks.

This makes the blockchain an ideally suitable storage system for information under certain conditions in various applications, where conventional databases are not the best option.

Blockchain technology allows different parties that do not trust each other to exchange data without the involvement of a central server. Transaction processing is carried out by users of the network, which has the main role of the consensus mechanism.

The sense of the development of decentralized control is in eliminating the risks of the network centralization. While using a centralized database, anyone who has access to it is able to make a damage or change the information stored in it. In this situation, users depend on the server administrators.

Blockchain allows you to store the currently relevant data, as well as all information that relates to previous periods. The blockchain is capable of storing the history of itself. Such databases grow and constantly expand the archives of their history and provide a picture of the current situation in real time [6].

\footnotetext{
* Corresponding author: andreeva ii@volsu.ru
} 


\section{Creating digital archives documents based on related data}

The technology of creating digital archives actually helps to connect the two worlds - the digital world and the physical world. A huge number of documents on the paper in archives, libraries, museums, courts and other public institutions are translated into digital form now $[7,8]$.

The most important feature of scanning technologies for cultural institutions is the extremely careful handling of the original. Planar scanners are used to ensure a noncontact scanning of the information from the media. For government agencies, which have to digitize large volumes of documents from standard A4 sheets, the performance of devices is fundamental. These criteria are met in the document scanners with a speed of up to 60 thousand sheets per working shift. But one scan for creating a digital archive is not enough, it is needed to index these images and create a directory. The cloud technologies that support the job distribution system among the thousands of employees participating in the project help to do this.

A toolkit for the development of digital archives is designed to create the means of publishing the information accumulated in the institution in a way that allows its integration into a common information environment of the semantic web and tools to support the preparation and publication of semantically marked documents, the development of web applications for publishing and processing research data.

The toolkit of the digital archive is built on the component architecture. The component is a key element of the component architecture. It is designed to meet the following requirements:

1. The component can be used in various systems.

2. The component does not keep information about specific software in which it is used.

3. It is allowed to create new components based on existing ones.

4. The component has known interface for interaction, but hides the details of its internal implementation.

5. Components are designed to have minimal dependencies on other components.

A typical example of components are the elements of the user interface (control). The component architecture focuses on the isolation of individual components and the organization of interaction between them. This style solves the problems of structuring applications and provides the following benefits:

- Ease of deployment. When a new version is available for the component, the old version is replaced without affecting the other components.

- Decrease in cost. The finished components of thirdparty manufacturers can be used to develop it.

- Reuse. The same components can be used in several applications.

- Reducing technical complexity. Typically, the components that make up one application are deployed within the same software container. This container controls the lifetime of components, the activation of them, the transmission of messages between components and so on.
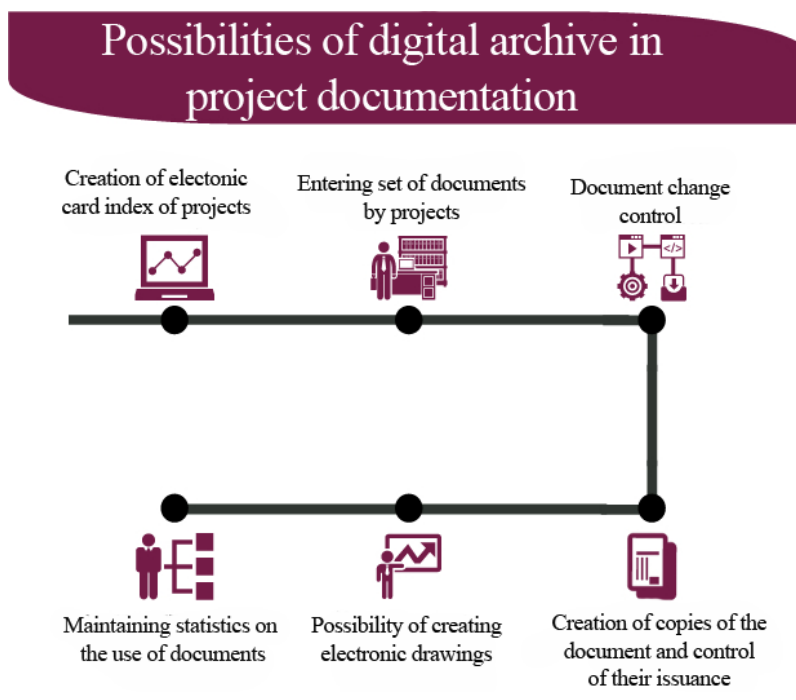

Fig.1. Digital archive capabilities.

It is possible to automate the execution of payment orders from the state with the help of technology of smart contracts on the basis of the blockchain-platform. Blokchain allows you to store all the necessary information for the work of civil servants. For example, the official person enters information, reports, acts and memos into the distributed registry and has access to them at any time. All information is stored in the digital form, and not in the form of deposits of documents in folders and on shelves.

Due to the possibility to make entries in the blockchain record about the right of ownership, civil and commercial contracts, there is no need for any intermediary links: archivists, notaries, accountants, clerks and even government employees [9].

\section{Information infrastructure of modern society in terms of providing state and municipal services}

The researchers believe that the structure of the municipal services as an institution consists of two main systemically organized parts. For example, G.V. Atamanchuk thinks that the municipal service consists of: a) norms, rules, standards, procedures, structures and other elements dictating the procedure for the exercise of municipal power, as well as the requirements for those directly involved in the municipal management of social processes (the legal component); b) citizens professionally trained and constantly participating in the performance of the competence of various municipal bodies (social component).

Thus, it can be seen that basically the municipal service has two main elements: legal and social.

However, in the context of the information society, the existing institution of the municipal service is under modernization [10]. The current stage of the 
administrative reforms in Russia is aimed at optimizing the structure and technologies of municipal government. This process affects both the social and legal components.

The fact is in conditions of development of the information society, the third component is the information component, which appears in the structure of the municipal service.

The main elements of the information infrastructure of the municipal government are various types of information support:

- the informational potential of the subjects of management (information needs and capabilities) necessary for the implementation of information activities;

- information flows, information resources involved in management;

- information systems, portals, sites used as a means of management;

- legal support of the information infrastructure.

The most important and complex thing in this structure is development and implementation of information systems.

At this moment in the Russian Federation there are 2 information systems designed to provide services to the public. The automatizated informational system (AIS) "Gosuslugi" (Figure 2) provides services of federal significance, for example, issuing civil and foreign passports, payment of fines, etc.

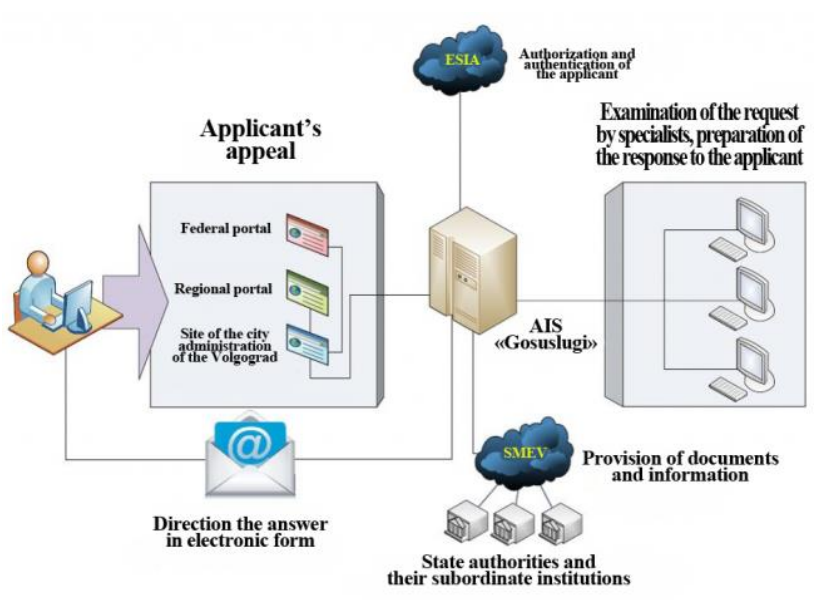

Fig.2. The scheme of functioning of the information system "GosUslugi".

The system formulates the package of documents required from the employees of the administration without involving programmers and also forms new municipal services. The service is provided on the administration's website. Statements from citizens are accepted electronically by filling out data entry forms according to the system settings. The description of services is placed on the Unified and Regional portals of state and municipal services in the information system "Register of public services", and the authorization of applicants to receive services is carried out using the
Federal Unified Identification and Authentication (ESIA).

Each region has a different structure of "My Documents". It represents a network of multifunctional centers on the basis of the AIS "Gosuslugi". But additionaly it is possible to obtain regional and municipal services not represented in it, for example, issuing certificates from house books, receiving compensation, etc. (Figure 3).

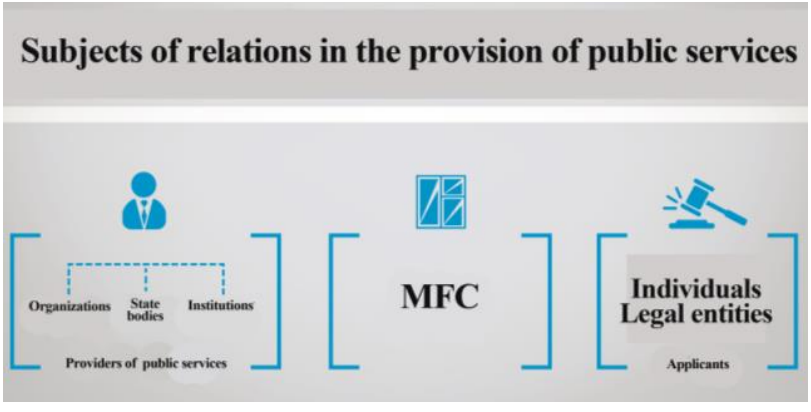

Fig.3. Subjects of providing public services.

We will discuss in more detail about the structure of multifunctional centers. There are 49 multifunctional centers on the territory of the Volgograd Region. Satisfaction of consumers from service providers is estimated as 4.97 out of 5 (Figure 4).

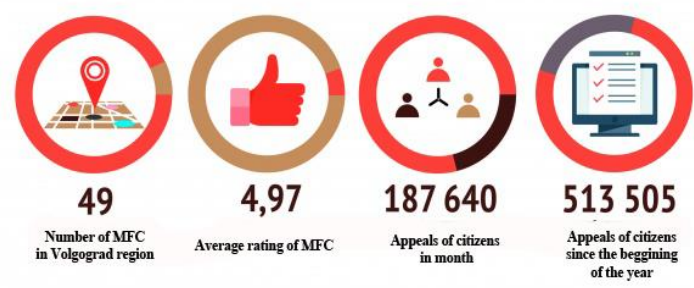

Fig.4. MFC statistics.

The number of services provided on the basis of the MFC amounted to more than 2 million completed applications (Figure 4), of which more than one million - for federal services, more than 600,000 - for municipal services. On the basis of the centers and offices "My Documents" (MFC) of the Volgograd region, a set of interrelated services is organized within the framework of "life situations", such as "Birth of a Child", "Change of Name", "Individual Housing Construction", "Opening Your Business" , "Change of residence", "Loss of documents", "Acquisition of living quarters", "Loss of a loved one" and "Retirement".

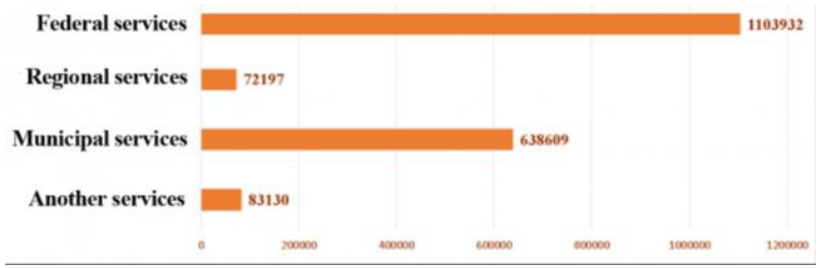

Fig.5. The amount of provided services. 


\section{The problem of protection and risk management of critical infrastructure}

The study of the management structure of the municipal entity has shown that its main elements are the social, legal and information components. The information component is the basis for building the information infrastructure of the management of the municipal formation and can be represented as a set of the following elements of information support:

- the information potential of the subjects of management (information needs and capabilities) necessary for the implementation of information activities;

- information flows, information resources involved in management;

- information systems, portals, sites used as management tools;

- legal provision regulating the efficiency of the information infrastructure.

The information potential of the subjects of management in the designing municipal programs for informatization and information policy is not noted. It also leads to inefficient work of the existing information infrastructure.

The analysis of the experience in the development and implementation of information infrastructures of the activities of the municipal government made it possible to identify a number of problems:

- the complexity of introducing informational system at the municipal level;

- a need to take into account generally accepted international standards in the development of informational system;

- the complexity of using unified informational system in various municipalities;

- financial problems of informational system implementation;

- inadequate qualification of municipal employees in terms of information competencies.

All the discussed problems of the development of information support for the activities of municipal government can acquire specificity depending on conditions. However, the most relevant of them is the problem of forming and realizing the information potential of municipal employees.

In order to modernize and develop the information and telecommunications infrastructure of multifunctional centers for the provision of state and municipal services in the Volgograd region, there is need for the following services:

1) Mobile application for applicants with additional information on sets of open data in the Volgograd region "My Documents".

2) Automation of accounting for paid services in a multifunctional center with the use of cash registers, means and methods for accepting payments.

3) Optimization of the local computer network of the institution, the construction of an information security system.
4) Automation of accounting of consumables for copying equipment (storage, transportation, refueling, repair). Accounting of paper.

5) Automation of the training process for employees of the multifunctional center using a mobile application and scoring knowledge.

6) The system of conducting and accounting for the organization of economic activity and the property complex of the institution.

7) Automation of calculation of motivation for employees of the multifunctional center on the basis of actually performed work (rendering of services).

8) Attestation of the state information system.

9) Development of information and telecommunications infrastructure.

10) Creation of the sphere of interactive games for citizens: "Public services - it is clear to everyone!"

11) Automated accounting of the work of the institution's employees and calculation of motivation.

In the framework of this paper, we will consider the principles of creating an application for pretenders with additional information on sets of open data.

This application, built into the site of the multifunctional center, should provide the opportunity to fill out forms for preparing applications for the provision of services to a multifunctional center.

Filling out the form means giving a personal information of a person for obtaining a particular service. According to the law on the storage of personal data, this information can not be kept in the server and is deleted after user closes the tab.

The scheme of actions in this situation is shown in Figure 6.

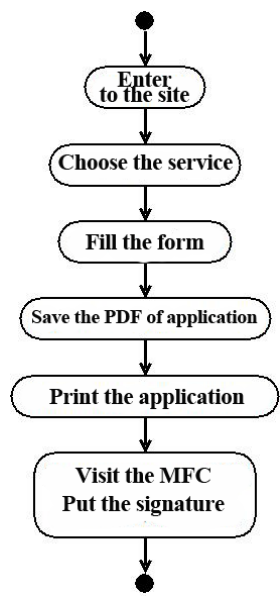

Fig.6. The block-scheme of actions.

Each regional and municipal service is represented by the Volgograd committees as technological schemes. Let us consider an example of parsing the technological scheme in Figure 7.

The essence of the modernization of this service is that the users on the site will fill out their personal data without saving them on the server. Data will be transferred to the application form and issued to the user as a completed application in the pdf format. At the next stage, the user must come with a printed application to the multifunctional center and sign in the presence of the 
representative of the MFC. This service will significantly shorten the time of service provision in the MFC because the operator does not need to enter independently the applicant's data. He will only need to register the applicant's appeal and send it to the appropriate body for execution.

\section{Conclusion}

The authors conclude that the information infrastructure of regional management can be understood as a set of the following elements: information potential of the subjects of management; information flows and resources; information instruments; legal provision regulating the efficiency of the information infrastructure. The research novelty lies in the substantiation of the necessity to include information potential of management subjects into the information structure of municipal management. The study of regional programs shows that this element is not taken into consideration, thus leading to the inefficient use of infware.

The automatization and modernization of popular services of the multifunctional centres of the Volgograd region are needed.

New services will be implemented in the near future, increase the efficiency of the work of the staff, reduce the time of reception of one applicant and simplify the work for all.

The authors are thankful to the Ministry of Education and Science of the Russian Federation (project No. 2.852.2017/4.6).

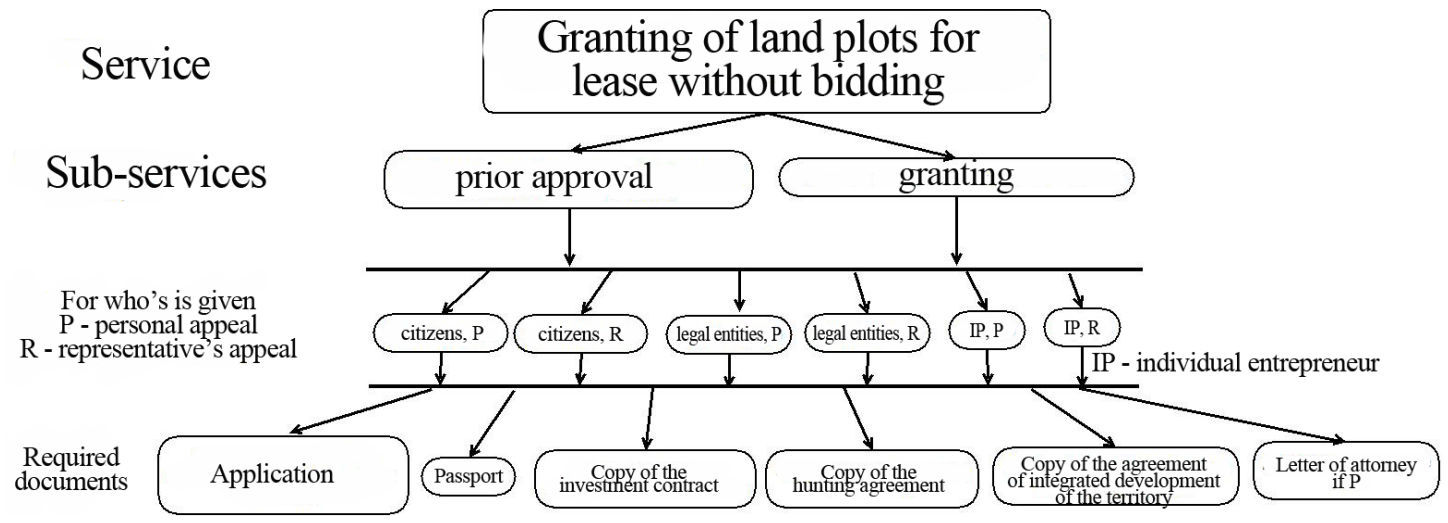

For whom it is:

$\mathrm{P}$ - personal appeal

$\mathrm{R}$ - representative's appeal

\section{Fig.7. Technological scheme.}

\section{References}

1. C. Ruehl, D. Ingenhoff, Journal of Communication Management 19 (3), 288 (2015)

2. D. Kim, J. Kim, Y. Nam, Quality \& Quantity 48 (5), 2605 (2014)

3. M. Misaki, T. Tsuda, S. Inoue, et al, IEEE Transactions on Semiconductor Manufacturing 30 (4), 328 (2017)

4. L. Aniello, R. Baldoni, E. Gaetani et al, IEEE 13th European Dependable Computing Conference, 151 (2017)

5. S. Smetana, C. Seebold, V. Heinz, Resources Conservation and Recycling 133, 229 (2018)

6. N. Payne, J.R. Baron, IEEE International conference on Big data, 2288 (2017)

7. S. Baldwin, Art Design \& Communication in Higher Education 17 (1), 25 (2018)

8. J.-H. Chang, P.-S. Chiu, Y.-M. Huang, International Review of Research in Open and Distributed Learning 19 (1), 1 (2018)
9. Y. Jiang, H. Dong, Lecture Notes in Computer Science 5173, 13 (2008)

10. I. Levin, Proceedings of TMCE 2014, 13 (2014) 